International Business Management 13 (6): 214-219, 2019

ISSN: $1993-5250$

(C) Medwell Journals, 2019

\title{
Motivation and Job Performance of Career Administrators in Universities in South-East, Nigeria
}

\author{
${ }^{1}$ Uche Calista Vita-Agundu, ${ }^{2}$ Pamela K. Asogwa, \\ ${ }^{1}$ Ngozi Hope Chinweuba and ${ }^{3}$ Chinyere Augusta Nwajiuba \\ ${ }^{1}$ Department of Educational Foundations, University of Nigeria Nsukka, Enugu State, Nigeria \\ ${ }^{2}$ Department of Language Studies, Enugu State College of Education (Technical), Enugu, Nigeria \\ ${ }^{3}$ Department of Educational Foundation, Faculty of Education, Alex Ekwueme Federal University, \\ Ndufu-Alike, PMB 1010 Abakaliki, Ebonyi State, Nigeria
}

\begin{abstract}
The study investigated the motivation and job performance of career administrators in universities in South East, Nigeria. The survey research design was employed for the study. The study was carried out in South East, Nigeria. A sample of 498 career administrators in universities in South-East Nigeria was used for the study. The instrument used for data collection was the university career administrator's motivation questionnaire and interview schedule. Results revealed that career administrators were motivated by the job itself, interpersonal relations and administration and supervision but were not motivated by salary and general working condition. Therefore, it was recommended that the government should ensure regular/prompt payment of salaries and also ensure that the general working conditions are favourable to adequately motivate career administrators to work. In-services and professional training programmes should be provided for career administrators to keep them abreast with the latest changes in their job.
\end{abstract}

Key words: Career administrators, motivation, job performance, universities, professional, salaries

\section{INTRODUCTION}

Education is widely accepted as a major instrument for promoting the socio-economic, political and cultural development of a nation. This explains the reason the developed countries of the world have always guarded their educational affairs with strictness and most deserved sense of commitment. Because of the importance of education to both individual and national life, the (Federal Republic of Nigeria, 2004) in her National Policy on Education categorized the education system into four levels namely: pre-primary, primary, secondary and tertiary levels which include polytechnic, colleges of education and universities. University is the highest educational institution for teaching and research in various disciplines for the acquisition of knowledge and the production of workforce and materials for personal and societal growth and development (Obeki, 2012). Universities make an optimum contribution to national development through relevant higher level manpower training. The primary goal of university education is to satisfy specific or general educational needs of the nation through the teaching of students, conducting research and dissemination of knowledge, together with other community service activities (Federal Republic of Nigeria, 2004). The achievement of this noble objective requires effective management of the system through proper utilization of human and material resources. This, according to Eze entails adhering to high standards in recruitment, continuous training and retraining based on identified needs, offering competitive schemes of remuneration and incentives in all the units of the university. In any university system, the registry is one of the units which carry out substantial non-academic duties with the registrar as the administrative head. The registrar department is the administrative heart of the university responsible for the routine administration of the university except those bothering on financial matters, account and academics. It is responsible for the secretarial services, analysis and storage of relevant statistics and nation to name a few. In achieving these tasks, the role of university career administrators becomes indispensable. University career administrators are full-time professional staff who implement minor routine policies and decisions in the university and is headed by the registrar (Adamji, 2013). Career administrators in this study are those personnel employed to work in the administrative arm of the university. The structure of university career administrators in descending order is as follows administrative assistant, administrative officer, assistant registrar, senior assistant registrar, principal assistant registrar, deputy registrar and registrar. Career administrators perform different functions under the supervision of deputy registrars who by their ranks

Corresponding Author: Ngozi Hope Chinweuba, Department of Educational Foundations, University of Nigeria, Nsukka, Enugu State, Nigeria 
constitute the unit heads. The major functions of university career administrators are to ensure proper interpretation and implementation of policies and decisions of the university which could be achieved through effective job performance.

Several arguments have been derived in performance and workers motivation. The assertion that in order for employee to perform, there is need to provide some motivations to encourage them to be committed to the organizational objectives while the contrary assumption is that good performance is not necessarily a product of rewards or motivators but it is induced by the interest one has in a particular act (Adair, 2007). In defining motivation, Ayub and Rafif (2011) agrees that it is an incentive which helps to energize and direct behaviour of the employee towards performing their duties. In the words of Akanbi (2003), motivation can either be intrinsic or extrinsic. Intrinsic motivation stems from motivations that are inherent in the job itself which the individual enjoys as a result of completing the task or attaining his goals. They include work itself, responsibility, recognition, achievement and advancement. Extrinsic motivations on the other hand are those that are external to the task. They include salary, interpersonal relationship with superiors and subordinates, physical working condition, organizational policy and administrative practices among others (Akanbi, 2003). Motivation in this study means the process of stimulating university career administrators to action to achieve the desired task. The motivational factors addressed in this study include salary, the job itself, general working conditions, interpersonal relationship, administration and supervision.

The university career administrators seem to complain of not being motivated with respect to the aforementioned motivational factors such as stagnation (no promotion), poor conditions of service including denial of financial benefits accrued from promotions, poor salaries compared with their counterparts in other universities outside South East, Nigeria. This could affect their performance and give rise to low morale and poor work attitude. When workers lack motivation, they tend to resort to anti-work behaviours such as absenteeism, negligence of duty, late-coming, failure to meet deadlines, display of open frustration and all these factors impact negatively on the performance and credibility of an organization (Herpen et al., 2005). There could be a likely relationship between motivation and employee performance in an organization, though, the relationship may differ depending on the sector and the influence of other extraneous variables. Akanbi (2003) found out that when there was an increase in motivation, there was also a corresponding increase in worker's performance. On the other hand, Stella (2008) found a negative correlation between motivation and job performance among staff. The main purpose of this research was to determine the motivation and job performance level of career administrators in universities in South East, Nigeria.

\section{MATERIALS AND METHODS}

The survey research design was employed for the study. The study was carried out in South East, Nigeria. It was delimited to all government-owned universities in the five states which make up South East, Nigeria, namely Abia, Anambra, Ebonyi, Enugu and Imo States. The South East, Nigeria, shares boundaries with Benue and Cross River states on the East, Delta and Edo states on the West, Rivers and Akwalbom states on the South, Kogi and Benue on the North, Anambra and Abia states on the South and Kogi and Benue states on the North. The "Igbos" constitutes the majority of the workforce in public universities in South-East, Nigeria. One prominent quality among them is that they are adventurous. They believe in moving around to explore every avenue. They like to be recognized and rewarded for a job well done. There is a general notion among the Igbos that when an individual is duly recognized and rewarded for a jobs well done, he/she will be pushed to do more. The population of this the study comprised all the 533 career administrators within ranks of administrative officer, assistant registrar and senior assistant registrar in the universities (Federal and State) in South-East Nigeria. The population is made up of 140 for Enugu State, 116 for Anambra State, 1114 for Abia State, 35 for Ebonyi State and 128 for Imo State. The population of career administrators was obtained from Registry and personnel units of each university in South East, Nigeria as at April 2015 and Association of Nigerian University Professional Administration (ANUPA) Directory (2014). A sample of 498 career administrators in universities in South-East Nigeria was used for the study. A multi-stage sampling technique was used to arrive at the number of the respondents. The instrument used for data collection was the University Career Administrator's Motivation Questionnaire (UCAMQ) and Interview Schedule (IS). The University Career Administrator's Motivation Questionnaire contains the following university career administrator's motivational factors job itself, salary, general working conditions, interpersonal relationship and administration and supervision. It was a 39-items instrument with a 4 point rating scale of Strongly Agree (SA), Agree (A), Disagree (D) and Strongly Disagree (SD). The questionnaire was face validated by four experts from the Department of Educational Foundations and one expert from the Department of Social Science Education all from University of Nigeria, Nsukka. The internal consistency coefficient obtained 0.55 for the 
job itself, 0.85 for salary, 0.74 for general working conditions, 0.70 for interpersonal relationship and 0.75 for administration and supervision with 0.92 as the overall. The results indicated that the questionnaire was reliable for the study. This is because according to Eze's guide for interpreting the Cronbach alpha reliability coefficient an alpha level equals to or $>0.5$ is acceptable and reliable. A direct delivery and retrieval method was employed in the administration of the questionnaire. The research assistants were properly briefed on the modalities of administration and retrieval of the questionnaire. A total of 498 copies of the questionnaire were distributed to the respondents and 344 were returned (69\%). Mean and standard deviation were used to analyze the descriptive part of the data collected. Items with mean of 0.50-1.49 was regarded "Strongly Disagree" (SD), items with mean of 1.50-2.49 was regarded as "Disagree" (D), items with mean of 2.50-3.49 was regarded as "Agree" (A) while items with mean of 3.50-4.49 was regarded as "Strongly Agree" (SA).

\section{RESULTS AND DISCUSSION}

Research question: What is the extent of the motivation of career administrators in public universities in South-East, Nigeria. The results of the data analysis relating to the research question are presented in Table 1-5.

The data in Table 1 shows the items from 1-7 have high means of $0.59,0.60,0.64,0.69,0.72,0.77$ and 0.85 , respectively. The cluster mean and standard deviation are 3.30 and 0.45 , respectively. The results show the respondent's opinion that career administrators are given enough responsibility at work and are given an opportunity to acquire useful skills. They are also of the view that career administrators undergo training and development on the job have job freedom to reduce monotony and have challenging work to perform. They also held that the location of the workplace is within their place of residence and are allowed to try their method of doing the job. The cluster mean and standard deviation shows that the respondents agreed that they are motivated in respect of job itself as of career administrators in public university in South East, Nigeria.
The data in Table 2 shows that only item 8 high mean score. The mean was 2.58 with a standard deviation of $1.11,1.89$ and 1.97 with standard deviations of $0.98,1.01$, $0.99,0.96,0.96$ and 1.10 , respectively. The cluster mean and standard deviation are 2.05 and 0.69 , respectively. The results indicated that the respondents only agreed that their monthly emolument is commensurate to their job schedule. They however, disagreed to prompt/regular payment of salary and that their university implements regular salaries, increments and bonuses. They also disagreed that their university implement regular salary review that fringe benefits are paid, promotion benefits are paid and their annual salary increment is paid. The cluster mean and standard deviation also showed that career administrators were motivated by the factor of salary.

The data in Table 3 indicated that items 15-8, 20 and 21 had high mean scores of $3.04,2.95,2.73,2.53,2.95$ and 2.77 with standard deviations of $1.09,1.09,1.09,1.18$ and 1.20 , respectively. Whereas items 19 and $22-24$ have low mean scores of $2.44,1.44$ and 1.73 with standard deviations of $1.06,1.21,0.78$ and 0.99 , respectively. The cluster mean and standard deviation were 2.48 and 0.54 , respectively. The results are an indication that respondents agreed that medical and office facilities are provided for their benefit and that equipment are provided with conductive office accommodation and that there is provision of residential accommodation and insurance for staff. However, they disagreed that there is an opportunity for continuing education/training and retraining that credit facilities/loans are accessible to staff that there is provision for oversea medical treatment and also that there is conducive physical environment. The cluster mean and standard deviation also indicated that the career administrators disagreed that they were motivated by their general working conditions.

The data in Table 4 shows that all the items from 25-31 have high mean scores of 2.50 the mean scores are $3.45,3.072 .96,2.94$ and 2.90 with standard deviations of $0.98,0.87,0.77,80$ and 87 , respectively. The results show the respondent's views that the work environment provides opportunities to be happy with co-workers and that there is an opportunity for interaction among staff during working. They also agreed that their

Table 1: Mean ratings on the extent of motivation due to (job itself) of career administrators in public universities in South East, Nigeria (N=344)

\begin{tabular}{lccc}
\hline Item statement (Job itself) & $\overline{\mathrm{X}}$ & $\mathrm{SD}$ & $\mathrm{Dec}$ \\
\hline I am given due recognition for the successful accomplishment of assigned tasks & 3.68 & 0.59 & $\mathrm{SA}$ \\
I am given enough responsibility at work & 3.45 & 0.60 & $\mathrm{~A}$ \\
There is an opportunity to acquire useful skills, training and development on the job & 3.34 & 0.64 & $\mathrm{~A}$ \\
There is job freedom to reduce monotony & 3.17 & 3.18 & 0.69 \\
I am given challenging work to perform & 3.16 & 0.72 & $\mathrm{~A}$ \\
The location of my workplace in within my place of residence & 3.12 & 0.77 & $\mathrm{~A}$ \\
I am given an opportunity to try my own method of doing the job & 3.30 & 0.85 & $\mathrm{~A}$ \\
Cluster mean & & $\mathrm{A}$ \\
\hline
\end{tabular}

$\overline{\mathrm{X}}:$ Mean, SD : Standard deviation, Dec.: Decision, A: Agreed, SA: Strongly agreed 
Int. Business Manage., 13 (6): 214-219, 2019

Table 2: Mean ratings on the extent of motivation due to the (salary) of career administrators in public university in South East, Nigeria $(\mathrm{N}=344)$

Items statement (Salary)

My monthly emolument is commensurate to my job schedule

There is prompt/regular payment of salary

My university observes fair policies related to salaries, increment and bonuses

My university implements regular salary review

Fringe benefits are paid

Promotion benefits are paid

My annual salary increment is paid

Cluster mean

\begin{tabular}{ccc}
$\overline{\mathrm{X}}$ & $\mathrm{SD}$ & $\mathrm{Dec}$. \\
2.58 & 1.11 & $\mathrm{~A}$ \\
2.01 & 0.98 & $\mathrm{D}$ \\
2.05 & 1.01 & $\mathrm{D}$ \\
1.98 & 0.99 & $\mathrm{D}$ \\
1.91 & 0.96 & $\mathrm{D}$ \\
1.89 & 0.96 & $\mathrm{D}$ \\
1.97 & 1.10 & $\mathrm{D}$ \\
2.05 & 0.69 & $\mathrm{D}$ \\
\hline
\end{tabular}

$\overline{\mathrm{X}}:$ Mean, SD: Standard deviation, Dec.: Decision, A: Agreed, SA: Strongly agreed

Table 3: Mean ratings on the extent of motivation due to the general working condition of career administrators in public universities in South East, Nigeria $(\mathrm{N}=344)$

\begin{tabular}{|c|c|c|c|}
\hline Items statement (Salary) & $\overline{\mathrm{X}}$ & $\mathrm{SD}$ & Dec. \\
\hline Medical facilities are provided for my benefit & 3.04 & 1.09 & $\bar{A}$ \\
\hline Office facilities are provided for my benefit & 2.95 & 1.09 & A \\
\hline Office facilities and equipment are provided & 2.73 & 1.09 & A \\
\hline There is conductive office accommodation & 2.53 & 1.09 & A \\
\hline There is an opportunity for continuing Education/training and retraining & 2.44 & 1.06 & A \\
\hline There is provision of residential accommodation & 2.95 & 1.18 & $\mathrm{D}$ \\
\hline Insurance for staff is available & 2.77 & 1.20 & A \\
\hline Credit facilities/loans are accessible to staff & 2.24 & 1.21 & $\mathrm{D}$ \\
\hline There is there provision for oversea medical treatment & 1.44 & 0.78 & $\mathrm{SD}$ \\
\hline There is conductive physical environment & 1.73 & 0.99 & $\mathrm{D}$ \\
\hline Cluster mean & 2.48 & 0.54 & $\mathrm{D}$ \\
\hline
\end{tabular}

Table 4: Mean ratings on the extent of motivation due to interpersonal relationship of career administrators in public university in South East, Nigeria $(\mathrm{N}=344)$

\begin{tabular}{|c|c|c|c|}
\hline$\underline{\text { Items statement (Salary) }}$ & $\overline{\mathrm{X}}$ & $\mathrm{SD}$ & Dec. \\
\hline The research environment provide opportunities to be happy with co-worker & 3.45 & 0.98 & $\mathrm{~A}$ \\
\hline There is an opportunity for interaction among staff during working hours & 3.18 & 0.87 & A \\
\hline My relationship with head of unit is cordial & 3.07 & 0.77 & A \\
\hline My relationship with colleagues is cordial & 2.96 & 0.76 & A \\
\hline The sense of teamwork in my unit is compelling & 2.98 & 0.77 & A \\
\hline Colleaguescover my duties in my absence & 2.94 & 0.80 & A \\
\hline The university- community relationship is cordial & 2.90 & 0.87 & A \\
\hline Cluster mean & 3.05 & 0.59 & \\
\hline
\end{tabular}

Table 5: Mean ratings on the extent of motivation of career administrators in public universities in South East, Nigeria due to Administration and supervision $(\mathrm{N}=344)$

\begin{tabular}{|c|c|c|c|}
\hline Items statement (Salary) & $\overline{\mathrm{X}}$ & $\mathrm{SD}$ & Dec \\
\hline My head delegates authority to me & 3.65 & 0.62 & $\mathrm{SA}$ \\
\hline There is fair treatment by the head of my unit & 3.58 & 0.61 & $\mathrm{SA}$ \\
\hline The supervision of my activities by my head of unit is intermittent & 3.41 & 0.69 & $\mathrm{~A}$ \\
\hline Decision taken by my head while dealing with staff related issues & 328 & 072 & A \\
\hline The procedure for constituting committees in the university is explicit & 3.22 & 0.77 & $\mathrm{~A}$ \\
\hline Observation of due process and the rule of law in the university is beyond reproach & 3.21 & 0.69 & A \\
\hline Heads methods rewarding achievement is fairly applied & 3.13 & 0.65 & A \\
\hline The head handles complaints/petitions from staff very well. & 2.97 & 0.71 & A \\
\hline Cluster mean & 3.31 & 0.44 & A \\
\hline
\end{tabular}

$\overline{\mathrm{X}}:$ Mean, SD : Standard deviation, Dec.: Decision, A: Agreed, SA: Strongly agreed

relationship with the head of unit and colleagues is cordial. More so, they agreed that a sense of teamwork in their unit is compelling and that there is an opportunity to be consulted for assistance by other members of staff. They agreed that colleagues cover their duties in their absence. Cluster mean and standard deviation indicated that career administrators were motivated by their interpersonal relationship.

The data in Table 5 revealed that all the items from 32-39 had high mean scores of $3.65,3.58,3.41$,
$3.28,3.13$ and 2.97 with standard deviation of $0.62, \ldots$, $61,0.69,0.72,0.77,0.69,0.65$ and 0.71 , respectively. The cluster mean and standard deviation are 3.31 and 0.44 , respectively. This result is an indication that the respondents agreed that their head delegates authority to them that there is fair treatment by the head of the unit and that supervision of their activities by the head of unit is intermitted. They held that decisions taken by their head while dealing with staff-related issues are always anchored on specified criteria that the procedure for 
constituting committees in the university is explicit and that the observation of due process and the rule of law in the university is beyond reproach. More, so, the respondents held that head's of rewarding achievement is fairly applied and that the head handles complaints/petitions from staff very well. The cluster mean and standard deviation also indicated that career administrators agreed that they were motivated by the administration and supervision. The responses from the interview schedule indicated that some were motivated while others believed that they were not motivated. Some stated that their promotion comes regularly and that it was enough motivation.

The findings of this study showed that career administrators are motivated by the job they do. This meant that they find their job interesting. This could be because they are given recognition when they accomplished assigned duties given enoughresponsibility or volume of work to perform, provide with the opportunity to undergo training and acquiring useful skill also motivates them. The finding is line with the research by Ugwuanyi (2014) who stated that academic staff is satisfied with their job. Concerning interpersonal relationships, the result showed that the work environment provides opportunities for career administrators to be happy and interact with their co-workers during working hours. This agreed with the finding by Matthew et al. (2009) that managers who practice effective interpersonal relationship in their workplace motivate the workers a great deal. It also agreed with the finding by Stella (2008) that the working relations at the district local government are effective to encourage performance. This means that effective or good interpersonal relationships will enable career administrators to understand other workers behaviours, cope with circumstances, control any situation (s) they find themselves in and properly interact with one another. The result on administration and supervision showed they constitute a source of motivation among career administrators. This finding is supported by the result by Onyiri (2007) that private school principals are more effective in administration due to close supervision by proprietors. This meant that if staff are monitored and supervise by the appropriate authority or employers, their level of motivation to work will likely increase.

The findings also revealed that career administrators were not motivated by their salary. This could be based on the fact that there was no prompt/regular payment of salary and the university does not implement regular salary review. Fringe benefits, promotion benefits and annual salary increment are not paid. The finding agreed with that by Stella (2008) that although, money is an important incentive to encourage good performance, salaries were perceived as inadequate and this influenced workers motivation negatively. The explanation for the finding is that when salaries are not being paid regularly/promptly or there is denial of financial benefits accruing from promotions or poor salaries compared with what their counterparts in other universities receive, this could affect career administrator's performance and give rise to low morale and poor work attitude. They may resort to anti-work behaviours such as absenteeism, negligence of duty, late-coming, failure to meet deadlines and display of open frustration among others. Similarly, career administrators were not motivated due to general working conditions. The reasons are that although, medical and office facilities, equipment and conducive office accommodation were provided for the benefit of career administrators they had no opportunity for continuing education/training and retraining, conducive physical environment among others. This result agreed with Ajayi et al. (2011) who found that work environment of academic staff in the universities was favourable in terms of physical facilities, information services and motivation and not with the general working condition of staff. It is also in line with the finding by Afful-Broni (2012) that working conditions and threats of layoffs were often than not given the least importance ranking than any of the other factors. This shows that the general working condition for career administrators can act as a strong determinant of their motivation to work. Theexcerpts from the interview participants are in agreement with the findings from the participants on the motivation of career administrators.

\section{CONCLUSION}

Career administrators were motivated by the job itself, interpersonal relations and administration and supervision but were not motivated by salary and general working condition. The government should ensure regular/prompt payment of salaries and also ensure that the general working conditions are favourable to adequately motivate career administrators to work. In-services and professional training programmes should be provided for career administrators to keep them abreast with the latest changes in their job.

\section{REFERENCES}

Adair, J., 2007. Leadership and Motivation: The Fifty-Fifty Rule and the Eight Key Principles of Motivating Others. Kogan Page, London, England, UK., ISBN:9780749450496, Pages: 160.

Adamji, S.S., 2013. Influence of higher educational qualifications and gender on the administrative competence of career administrators in universities in the North Central zone of Nigeria. Ph.D Thesis, University of Nigeria, Nsukka, Nigeria.

Afful-Broni, A., 2012. Relationship between motivation and job performance at the University of Mines and Technology, Tarkwa, Ghana: Leadership lessons. Creative Educ., 3: 309-314. 
Ajayi, I.A., O.O. Awosusi, B.B. Arogundade and H.T. Ekundayo, 2011. Work environment as correlate of academic staff job performance in South West Nigerian universities. Eur. J. Educ. Stud., 3: $1-9$.

Akanbi, P.A., 2003. Influence of extrinsic and intrinsic motivation on employees performance in Ogun State University. J. Manage., 12: 203-203.

Ayub, N. and S. Rafif, 2011. The relationship between work motivation and job satisfaction. Pak. Bus. Rev., 13: 332-347.

Federal Republic of Nigeria, 2004. National Policy on Education. NERDC Press, Lagos, Nigeria,

Herpen, M.V., M.V. Praag and K. Cools, 2005. The effects of performance measurement and compensation on motivation: An empirical study. J. De Economist, 153: 303-329.

Matthew, J., Grawhich and L.K. Barber, 2009. Are you focusing both employees and organizational outcome? Organizational Health Initiative, 4: 1-5.
Obeki, S.O., 2012. Administrative Skills, Procedures and best Practices for University Administrators and Administrative Personnel. Mindex Publishing Company Limited, Benin City, Nigeria,

Onyiri, O.U.J., 2007. Principals personal attributes and administrative effectiveness of public and private secondary schools in Rivers State. M.Ed Thesis, Rivers State University of Science and Technology, Port Harcourt, Nigeria.

Stella, O., 2008. Motivation and work performance: Complexities in achieving good performance outcomes; a study focusing on motivation measures and improving workers performance in Kitgum district local government. Master Thesis, Graduate School of Development Studies, Institute of Social Studies, The Hague, The Netherlands.

Ugwuanyi, J.C., 2014. Demographic variables as correlates of job satisfaction among academic staff of colleges of education in South East, Nigeria. Ph.D Thesis, University of Nigeria, Nsukka, Nigeria. 